\title{
Agustina Giraudy, Eduardo Moncada y Richard Snyder (Eds.), Inside countries: Subnational research in comparative politics, Cambridge, Cambridge University Press, 2019, 374 pp. https://doi.org/10.1017/9781108678384
}

Reseña por Javier Pérez Sandoval*

Licencia Creative Commons Atribución-NoComercial (CC BY-NC) 4.0 Internacional

Perfiles Latinoamericanos, 29(58) | 2021 | e-ISSN: 2309-4982 DoI: dx.doi.org/10.18504/pl2958-016-2021

\section{Inside countries: reduciendo la escala de análisis en el análisis político ${ }^{1}$}

E

n un esfuerzo por superar el sesgo nacional (Lijphart, 1975), durante la última década la ciencia política, en lo general, y la política comparada, en lo particular, han redoblado sus esfuerzos por identificar y explicar el cómo y el porqué determinados fenómenos sociopolíticos relevantes varían al interior de distintos países.

En su libro recientemente coeditado, Agustina Giraudy y Richard Snyder — también autores de Democrats and Autocrats y Politics after Neoliberalismhan reunido contribuciones sólidas que de manera concisa discuten los temas más apremiantes y los problemas metodológicos que enfrenta la literatura emergente sobre investigación subnacional en la política comparada. Para examinar coherentemente el libro aquí reseñado, se propone una primera sección en la que se explora sucintamente su contenido, para después, en la segunda, destacar sus principales fortalezas y debilidades.

En Inside Countries, Agustina Giraudy y Richard Snyder, junto con quince colaboradores, concentran el debate en torno a cuatro temas centrales: I) diseño y métodos de investigación, II) regímenes y representación, III) Es-

* Candidato a Doctor en Política por la Universidad de Oxford. Tutor y Asistente Graduado de Enseńanza del Departamento de Política y Relaciones Internacionales, Universidad de Oxford (Reino Unido) javipersa@gmail.com | ORCID: https://orcid.org/0000-0002-7410-7201

1 Escrita originalmente en inglés con el título "Scaling down Inside Countries", la traducción de esta reseña al español es de Jimena Hernández León. 
tados y seguridad y IV) desarrollo social y económico. Con contribuciones lúcidas de Caroline Beer, Matthew Ingram y Hillel Soifer, entre otros, el libro ofrece una visión completa del giro subnacional en la ciencia política, y funge como un faro tanto para jóvenes investigadores como para experimentados académicos.

Los capítulos sobre las dinámicas de los regímenes subnacionales exploran la variación territorial respecto a las relaciones ejecutivo-legislativas y la legislación de género en los diferentes estados de Rusia y México. Por una parte, Gavril Bilev explora cómo los gobernadores usan los criterios de elegibilidad de las alcaldías para ganarse el favor de los congresos locales y debilitar así los mecanismos de check \& balances. Caroline Beer, por otro lado, presenta un complejo argumento causal multinivel, observando cómo los actores internacionales y la opinión pública configuran y condicionan la legislación estatal sobre el aborto y la violencia contra las mujeres.

Las secciones que discuten temas de seguridad y desarrollo socioeconómico destacan la trascendencia del locus decisorio para comprender el conflicto civil armado, así como la partidización del apoyo federal en la lucha contra los cárteles del crimen organizado a lo largo y ancho de las entidades mexicanas. Prerna Singh, Sunila S. Kale y Nimah Mazaheri, así como Meg Rithmire, resaltan respectivamente la relevancia de la solidaridad social, las organizaciones de la sociedad civil y los territorialmente distintos regimenes de propiedad, al explicar el desarrollo en las ciudades en China e India.

En cuanto a los métodos, mientras que Imke Harbers y Matthew Ingram nos invitan a tomar el espacio en serio - por razones conceptuales, teóricas y analíticas-, Hillel Soifer esquematiza y problematiza los supuestos subyacentes de la investigación subnacional. Conjuntamente, exhortan a los profesionales de este tema a que piensen cuidadosa y explícitamente sobre su nivel de análisis, destacando el desafío que presenta el permanecer consistente desde el diseño hasta la ejecución de cualquier proyecto de investigación.

En términos de fortalezas y debilidades, Inside Countries ofrece al menos tres contribuciones clave: a) esquematiza y describe los distintos estilos y lógicas argumentativas comúnmente utilizadas en la investigación subnacional; b) muestra que esta puede mezclar de forma efectiva y creativa herramientas cuantitativas, cualitativas y experimentales; y por último y como esfuerzo conjunto de editorial, editores y colaboradores, c) la sección III de la obra sirve como claro ejemplo de que el giro subnacional en la política comparada conduce a la disciplina hacia un terreno fértil y emocionante.

Frente a las múltiples fortalezas del libro y los capítulos individuales advertimos varias debilidades. Por limitaciones de espacio aquí examino brevemente un asunto menor respecto a la caracterización que los editores realizan de la in- 
vestigación subnacional, así como dos críticas significativas sobre la elaboración de teorías en la investigación subnacional.

En el meta-análisis de la investigación subnacional, Giraudy y Snyder clasifican los distintos tipos de teorías y categorizan los vínculos entre nivel de análisis y causalidad. Si bien la mayor parte de la clasificación sugerida indica claramente su intención, la distinción entre procesos ascendentes (bottom-up) o descendentes (top-down) es problemática porque choca con la distinción clásica en la asignación de agencia (Parsons, 2007). Este problema menor se puede resolver fácilmente al clasificar a aquellos procesos en los que los eventos subnacionales dan forma a fenómenos nacionales como impulsos desde la periferia (periphery-driven processes), y a los que postulan la relación inversa como procesos con impulsos desde el centro (center-driven processes). Este refinamiento aclararía la distinción entre la dirección espacial de un proceso y si son las élites o fuerzas sociales los principales agentes causales.

Un segundo problema que requiere una mayor exploración son los límites teóricos y empíricos en los que se incurre al reducir la escala (scaling down). Como una posible solución para el problema de la unidad de área modificable (MAUP, por sus siglas en inglés), Soifer sugiere que una decisión a priori teórica y explícita es una condición sine qua non para la investigación subnacional. Mientras que es cierto que existen dinámicas relevantes que tienen lugar más allá de los límites administrativos-jurisdiccionales, la reducción de escala ad hoc presenta el riesgo de paralizar nuestra capacidad de generalizar y acumular conocimiento. En consecuencia, el discutir y distinguir más a fondo tanto los límites como los criterios que contornean lo subnacional es un paso necesario para fortalecer la evidencia, la teoría y el método.

Por último, mientras que el libro destaca y teoriza enfáticamente la importancia del espacio, los editores y los colaboradores dejan al margen al tiempo y a la historia. Pierson (2004), Mahoney \& Rueschemeyer (2003) y los defensores del análisis histórico comparado han subrayado cómo el desentramar las secuencias, los procesos de larga duración, las trayectorias dependientes (path dependence) y los legados históricos, ha mejorado nuestra comprensión de acontecimientos políticos relevantes. Por consiguiente, la intersección entre el giro temporal y el giro subnacional supone el siguiente paso lógico en la investigación subnacional, ofreciendo un terreno fértil y abundante tanto para los comparativistas en formación como para los investigadores más consolidados.

Inside Countries traza el camino recorrido por la investigación subnacional. En ese sentido, el libro delinea los temas y contornea algunos de los desafíos metodológicos y teóricos de la reducción de escala. Al mapear su desarrollo, el libro también permite a los lectores intuir y cuestionar el futuro de esta corriente de estudio. 
En resumen, con un interesante meta-análisis de la investigación subnacional y con excelentes estudios que - al analizar dinámicas políticas en regiones tan distintas como Rusia y América Latina- ejemplifican su potencial, el nuevo volumen de Giraudy y Snyder se perfila para convertirse en un texto clave para la discusión entre estudiantes tanto universitarios como de posgrado.

\section{Referencias}

Lijphart, A. (1975). The comparable-cases strategy in comparative research. Comparative Political Studies, 8(2), 158-177. https://doi.org/10.1177/001041407500800203

Mahoney, J., \& Rueschemeyer, D. (Eds.). (2003). Comparative historical analysis in the social sciences. Cambridge University Press. https://doi.org/10.1017/CBO9780511803963

Parsons, C. (2007). How to map arguments in political science. Cambridge University Press.

Pierson, P. (2004). Politics in time: History, institutions and social analysis. Princeton University Press. https://doi.org/10.1515/9781400841080 